\title{
Stabilizers for Osmium Isotopes in Microwave-Irradiated Acid Digestion and Inductively Coupled Plasma Mass Spectrometry Analysis
}

\author{
Nobuyuki Takayama,* Tetsuya Yoneda, Kenji Takebayashi, Masaru Ogasawara, and \\ Kiyoshi Takatsu \\ Toyama Prefectural Institute for Pharmaceutical Research; 17-1 Naka-taikouyama, Imizu, Toyama 939-0363, Japan. \\ Received August 27, 2021; accepted November 4, 2021
}

\begin{abstract}
Osmium is defined in the international council for harmonization (ICH-Q3D) guidelines as an element whose concentration can be determined by validated methods including microwave-assisted nitric acid digestion and inductively coupled plasma mass spectrometry. However, microwave digestion using nitric acid is known to result in osmium recoveries higher than the theoretical values in spiked tests because of the formation of highly volatile osmium tetroxide in an oxidation reaction. To stabilize osmium, the addition of thiourea as a complexing agent has been tested and proved its utility. It remains unclear whether other compounds can prevent the over-recovery of osmium. In this study, we investigated four compounds, thiourea, ascorbic acid, sodium sulfite, and potassium metabisulfite, that could reduce the overestimation of osmium isotopes. The minimum amounts of thiourea, ascorbic acid, sodium sulfite, and potassium metabisulfite required to stabilize $10 \mathrm{ng} / \mathrm{mL}$ osmium in blank matrix were $1.0,1.0,2.5$, and $2.5 \mathrm{~g} / \mathrm{L}$, respectively. The relative standard deviations obtained from 12 analyses for each stabilization solution were less than $3.3 \%$ in thiourea, $\mathbf{1 2 . 7 \%}$ in ascorbic acid, $\mathbf{9 . 0 \%}$ in sodium sulfite, and $10.6 \%$ in potassium metabisulfite. The stabilization solutions were investigated in a digested tablet matrix and were found to be effective. The impact of adding stabilization solutions on the determination of all ICH-Q3D element concentrations was also evaluated. As stabilization solutions had a small or significant impact on the determination of some elements, it was concluded that osmium determination should be conducted independently.
\end{abstract}

Key words inductively coupled plasma mass spectrometry; osmium determination; stabilization solution; microwave-assisted digestion; spike recovery test

\section{Introduction}

It is important to ensure the safety of medicines in the pharmaceutical industry. There are many cases where pharmaceuticals can be contaminated with toxic elements used in the production process. In recent years, much discussion has gone into unifying standards related to toxic metal impurities. The criteria to control toxic metal levels have been defined in the Q3D guidelines by the International Conference on Harmonization (ICH), and permitted daily exposures (PDE) have also been established. The guidelines define the maximum amounts of various impurity elements that can be contained in drug products. ${ }^{1)}$

The United States Pharmacopeia (USP) chapter (231) is a colorimetric determination method, which reports the sum of ten heavy metals present in a sample. This test has been used for a long time but was recently replaced by USP chapter (232) elemental impurities, and chapter (233) elemental impurities procedures. ${ }^{2,3)}$ The revised version of European Pharmacopeia chapter 2.4.20 also details the determination of elemental impurities. ${ }^{4)}$ Furthermore, supplement II chapter 2.66 to the Japanese Pharmacopoeia 17th edition contains details of procedures to control elemental impurities.5) Although there are some differences among these pharmacopeias, the common points are that the spike recovery test should be in the range $70-150 \%$, the relative standard deviation (RSD) obtained from a six-replicate spike recovery test should be $\leq 20 \%$, and repeatability analysis against a total number of 12 analyses should show RSD $\leq 25 \%$. Numerous methods to analyze various elements have been reported. ${ }^{6-12)}$ Inductivity coupled plasma atomic (optical) emission spectroscopy (ICP-AES or
ICP-OES) and inductivity coupled plasma mass spectrometry (ICP-MS) are described in USP chapter (233). ICP-MS is one of the most effective methods to determine the concentrations of metal elements because the ICP-MS can detect extremely low-level metal concentrations even below those required by the regulations. Therefore, this method is suitable for the analysis of impurity elements in drug products. ${ }^{13)}$

In many cases, however, sample pretreatment is necessary for quantitative analysis of metals, because the sample must be introduced into the ICP-MS instrument in a liquid state. ${ }^{14,15)}$ Therefore, solid samples, such as tablets, should be decomposed in a solution. In most cases, the microwave-assisted digestion method has been employed. The digestion can be practiced in a closed vessel, which prevents the loss of volatile elements. For these reasons, many papers regarding pharmaceutical analysis have included the decomposition method. ${ }^{16-19)}$

Osmium (Os) is one of the elements defined in the Q3D guidelines and belongs to the platinum group of metals. Osmium often forms osmium tetroxide $\left(\mathrm{OsO}_{4}\right)$ by reaction with air. Osmium tetroxide is used as a catalyst for the dihydroxylation of alkenes during drug synthesis. According to the Q3D guidelines, osmium is categorized as class $2 \mathrm{~B}$, and controls should be implemented to ensure that the PDE value is not exceeded if the element is used by design.

However, there is the problem that osmium is often overestimated after microwave digestion. This phenomenon is observed when the osmium oxidation state is transmuted. Osmium can be easily oxidized under acidic conditions; it then forms osmium tetroxide, which is a volatile species. Under such conditions, 
osmium tetroxide is volatile in the spray chamber and gets introduced into the ICP-MS system in large excess. Because of this, the amount of osmium can be overestimated.

Venzago et al. reported a technique to determine the quantity of osmium accurately, and it also met the requirements of USP chapter (233). ${ }^{20)}$ Their improved method involved applying a prepared stabilization solution containing acetic acid, thiourea, and ascorbic acid for osmium determination. Thiourea made a complex with osmium, which stabilized the osmium in solution. ${ }^{21-23)}$ They could obtain good spike recovery values and precision. The crucial issue for obtaining the highly sensitive results is to change the chemical form of the osmium from osmium tetroxide to another stable state. It is speculated that antioxidative activity could transform osmium tetroxide to normal osmium and thereby help alleviate osmium overestimation. In line with this idea, we considered that there is some room to investigate other compounds possessing antioxidative activity that could stabilize the osmium. Ascorbic acid and sodium sulfite have antioxidative activity and are used as preservatives and inhibitors of discoloration in the food and cosmetics industries; potassium metabisulfite is used as a bleaching and antioxidizing agent. However, there are few reports on the use of such compounds as a stabilizer in ICP-MS spike recovery tests. The advantage of using inorganic antioxidants, such as sodium sulfite and potassium metabisulfite, is that they can avoid soot generation during plasma formation, which is the case when using organic compounds such as thiourea. The purpose of this study is to expand the knowledge base of stabilization solutions to quantitate osmium. The reagents used for the experiment must not contain metal atoms in their structures because the examination is conducted to accurately determine metals present in the drugs. Ascorbic acid, sodium sulfite, and potassium metabisulfite were selected as the reducing reagents and evaluated by spike recovery tests using an ICP-MS method and compared against thiourea, a known osmium stabilizer (Fig. 1). These reducing reagents do not contain metals in their structures and are easy to acquire commercially. Pravastatin sodium, hydroxymethylglutaryl-CoA (HMG-CoA) reductase inhibitor, and doxazosin mesylate, an $\alpha 1$-adrenergic receptor antagonist, are drugs that are used worldwide and were chosen as model drugs for the spike recovery tests in this study to address whether the selected stabilizing reagents could prevent osmium overestimation in the presence of medicines. The results showed that all reagents worked as stabilizers and enabled quantitative osmium determination.<smiles>NC(N)=S</smiles>

Thiourea<smiles>O=S([OH2+])[18OH]</smiles>

Sodium sulfite<smiles>O=C1O[C@H]([C@@H](O)CO)C(O)=C1O</smiles>

Ascorbic acid<smiles>[Z70]S(=O)S(=O)(=O)[O+]</smiles>

Potassium metabisulfite
Fig. 1. Chemical Structures of the Stabilization Reagents

\section{Experimental}

Chemicals and Reagents Seventy percent nitric acid and $35 \%$ hydrochloric acid for digestion, thiourea, ascorbic acid, sodium sulfite and potassium metabisulfite for stabilization solutions, and sodium chloride, potassium chloride, sodium sulfate and potassium sulfate for neutral solutions were purchased from FUJIFILM Wako Pure Chemical Corporation (Osaka, Japan). Pravastatin sodium tablets were purchased from Sawai Pharmaceutical (Osaka, Japan). Doxazosin mesylate tablets were purchased from Nissin Pharmaceutical (Yamagata, Japan). The Os standard $(1000 \mu \mathrm{g} / \mathrm{mL}), \mathrm{ICH} / \mathrm{USP}$ oral target elements standard A (Hg: $30 \mu \mathrm{g} / \mathrm{mL}$, As: $15 \mu \mathrm{g} / \mathrm{mL}, \mathrm{Cd}, \mathrm{Pb}: 5 \mu \mathrm{g} / \mathrm{mL}$ ), ICH/USP oral target elements standard B (Ni: $200 \mu \mathrm{g} / \mathrm{mL}, \mathrm{Ag}$, Se: $150 \mu \mathrm{g} / \mathrm{mL}, \mathrm{V}: 100 \mu \mathrm{g} / \mathrm{mL}$, Co: $50 \mu \mathrm{g} / \mathrm{mL}$, Tl: $8 \mu \mathrm{g} / \mathrm{mL})$, ICH/USP oral target elements standard C (Au, Ir, Os, Pd, Pt, $\mathrm{Rh}, \mathrm{Ru}: 100 \mu \mathrm{g} / \mathrm{mL}$ ), ICH/USP oral target elements standard D (Cr: $11000 \mu \mathrm{g} / \mathrm{mL}, \mathrm{Sn}: 6000 \mu \mathrm{g} / \mathrm{mL}, \mathrm{Cu}, \mathrm{Mo}: 3000 \mu \mathrm{g} / \mathrm{mL}$, Ba: $1400 \mu \mathrm{g} / \mathrm{mL}, \mathrm{Sb}: 1200 \mu \mathrm{g} / \mathrm{mL}$, Li: $550 \mu \mathrm{g} / \mathrm{mL})$ and multielements internal standard (Te: $25 \mu \mathrm{g} / \mathrm{mL}$, Sc: $10 \mu \mathrm{g} / \mathrm{mL}, \mathrm{Ge}$, In, Lu, Bi: $5 \mu \mathrm{g} / \mathrm{mL}$ ) were purchased from Agilent Technologies (Santa Clara, CA, U.S.A.). All solutions for microwave digestion, standard solutions, internal standard, and samples were prepared by using ultra-pure water produced by a purification system in our laboratory (Millipore, Molsheim, France).

Apparatus All ICP-MS measurements were carried out by an ICP-MS 7900 (Agilent Technologies). The system was composed of an automated sampler, peristaltic pump, quartz spray chamber, plasma ionization source, ion lens, octopole reaction system cell, mass spectrometer section (quadrupole mass filter), and detector. More details regarding instrumental and analytical conditions are summarized in Table 1.

The microwave digestion system (Anton Paar GmbH, Graz, Austria) was operated as the power control program. The diluted standard Os $(10 \mu \mathrm{g} / \mathrm{mL})$ was spiked into a Teflon vessel after adding digestion solvents, and the system was run under the following power program: $350 \mathrm{~W}$ maintained for $15 \mathrm{~min}$, increasing to $700 \mathrm{~W}$ for $15 \mathrm{~min}, 700 \mathrm{~W}$ maintained for $20 \mathrm{~min}$, and cooling down to $50^{\circ} \mathrm{C}$.

Preparation of Stabilization Solutions and Neutral Solutions Stabilization solutions were prepared by dissolving thiourea, ascorbic acid, sodium sulfite, and potassium metabisulfite with ultra-pure water to a concentration of $20 \mathrm{~g} / \mathrm{L}$. These stabilization solutions were used to prepare spiked sam-

Table 1. ICP-MS Instrument Parameters for the Analytical Tests

\begin{tabular}{lc}
\hline \hline RF power $(\mathrm{kW})$ & 1550 \\
Plasma gas flow rate $(\mathrm{L} / \mathrm{min})$ & 15.0 \\
Auxiliary gas flow rate $(\mathrm{L} / \mathrm{min})$ & 0.90 \\
Dilution gas flow rate $(\mathrm{L} / \mathrm{min})$ & 0.00 \\
Nebulizer gas flow rate $(\mathrm{L} / \mathrm{min})$ & 1.08 \\
Collision gas flow rate $(\mathrm{mL} / \mathrm{min})$ & $4.3(\mathrm{He})$ \\
Spray chamber temperature $\left({ }^{\circ} \mathrm{C}\right)$ & 2 \\
Skimmer and sampler cones & Nickel \\
Stabilization delay $(\mathrm{s})$ & 40 \\
Sample uptake delay $(\mathrm{s})$ & 30 \\
Peristaltic pump velocity $(\mathrm{rps})$ & 0.3 \\
Rinse time $(\mathrm{s})$ & 30 \\
Sweep & 100 \\
Replicate & 3 \\
Detector & Electron multiplier detector \\
\hline
\end{tabular}


ples after digestion. Neutral solutions were prepared by dissolving sodium chloride, potassium chloride, sodium sulfate, and potassium sulfate-like stabilization solutions.

Preparation of Spiked Samples In the experiments to evaluate the effects of stabilization solutions in a blank matrix, the spiked samples were prepared without tablets. The samples for the spike recovery tests were prepared by dilution of the standard osmium solution. Digestion solvents, $6 \mathrm{~mL}$ of ultrapure water, $3 \mathrm{~mL}$ of nitric acid, and $1 \mathrm{~mL}$ of hydrochloric acid were added into the Teflon vessels, then $50 \mu \mathrm{L}$ of diluted standard Os $(10 \mu \mathrm{g} / \mathrm{mL})$ was added into the vessels. The vessels were tightly closed with caps and irradiated by microwaves, as described by the above power program. After microwave digestion, $2 \mathrm{~mL}$ of solution was transferred into a $10 \mathrm{~mL}$ volumetric flask, and stabilization solutions were added to the flask to adjust at five different concentrations: 10, 7.5, 5.0, 2.5 and $1.0 \mathrm{~g} / \mathrm{L}$. Then, the total volume of the spiked samples was adjusted to $10 \mathrm{~mL}$ with ultra-pure water. The final concentrations of nitric acid, hydrochloric acid, and spiked Os were 4.2, $0.7 \%$, and $10 \mathrm{ng} / \mathrm{mL}(\mathrm{ppb})$, respectively.

In the experiments to evaluate the effects of stabilization solutions in a digested tablet matrix, the spiked samples were prepared with tablets. Pravastatin sodium tablets and doxazosin mesylate tablets were employed. Tablets were put into Teflon vessels, and the digestion solvents were added. The sub- sequent procedures after adding the digestion solvents were performed in the same way as described above. The scheme to prepare samples is shown in Fig. 2.

Preparation of Calibration Standards and Internal Standard The standard Os solutions for the calibration curves were prepared at seven different levels: $0,1,5,10,15,30$, and $50 \mathrm{ng} / \mathrm{mL}$. Nitric acid and hydrochloric acid were added into the volumetric flasks to final concentrations of 4.2 and $0.7 \%$, respectively. ${ }^{209} \mathrm{Bi}$ was selected as the internal standard for Os determination. The internal standard was diluted 100-fold, and nitric acid and hydrochloric acid were added to the diluted internal standard solution to create the same concentration as those in the standard solutions. The prepared internal standard solution and standard Os solution were introduced into the spray chamber online using a peristaltic pump by an autosampler. Os was detected with $m / z$ at $186,187,188,189,190$, and 192 respectively by ICP-MS.

\section{Results and Discussion}

Linearity of Calibration Curves for Osmium Isotopes The calibration curves were obtained by taking measurements of a blank and six different concentrations of standards ranging from 1 to $50 \mathrm{ng} / \mathrm{mL}$. The parameters for each Os isotope calibration curve are summarized in Table 2. All of the correlation coefficients met the acceptance criteria in USP (233)

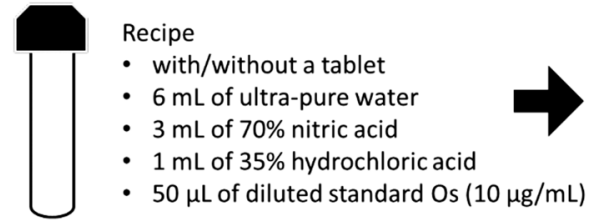

Teflon vessels ${ }^{a}$

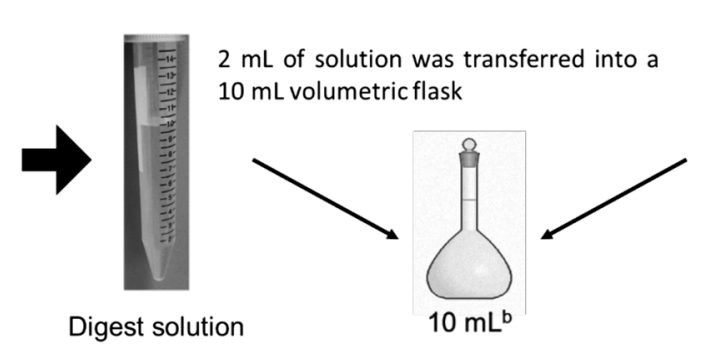

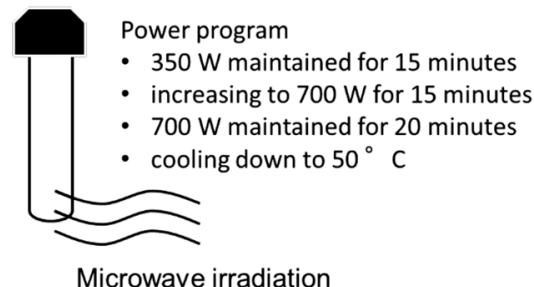

Adding a moderate amount of $20 \mathrm{~g} / \mathrm{L}$ stabilization solutions to adjust to different concentrations

Final concentrations

- nitric acid $4.2 \%(\mathrm{v} / \mathrm{v})$

- hydrochloric acid $0.7 \%(\mathrm{v} / \mathrm{v})$

- spiked Os $10 \mathrm{ng} / \mathrm{mL}$

Fig. 2. Schematic Procedure of the Preparation of the Samples

${ }^{\mathrm{a}}$ Teflon vessels: The concentrations of nitric acid, hydrochloric acid, and Os were approximately $21,3.5 \%$, and $50 \mathrm{ng} / \mathrm{mL}$ after adding digestion solvents. ${ }^{\mathrm{b}} 10$ - $\mathrm{mL}$ volumetric flask: Moderate amounts of $20 \mathrm{~g} / \mathrm{L}$ stabilization solution were added; for example, to adjust to $5 \mathrm{~g} / \mathrm{L}$ stabilization solution, $2.5 \mathrm{~mL}$ of $20 \mathrm{~g} / \mathrm{L}$ stabilization solution were added, $2 \mathrm{~mL}$ of digestion solution were also transferred to the $10 \mathrm{~mL}$ volumetric flask, and the volume was made up with pure water. The concentrations of nitric acid, hydrochloric acid, and Os were $4.2,0.7 \%$, and $10 \mathrm{ng} / \mathrm{mL}$, respectively.

Table 2. Summary of the Calibration Linearity

\begin{tabular}{|c|c|c|c|c|c|}
\hline & $R^{a)}$ & Slope & Intercept & $\mathrm{LOD}^{b)}(\mathrm{ng} / \mathrm{mL})$ & $\mathrm{BEC}^{c)}(\mathrm{ng} / \mathrm{mL})$ \\
\hline${ }^{186} \mathrm{Os}$ & 0.9998 & $6.4 \times 10^{-3}$ & $1.3 \times 10^{-4}$ & $1.0 \times 10^{-2}$ & $2.0 \times 10^{-2}$ \\
\hline${ }^{187} \mathrm{Os}$ & 0.9999 & $6.4 \times 10^{-3}$ & $8.0 \times 10^{-5}$ & $2.3 \times 10^{-2}$ & $1.2 \times 10^{-2}$ \\
\hline${ }^{188} \mathrm{Os}$ & 0.9997 & $5.6 \times 10^{-2}$ & $6.7 \times 10^{-4}$ & $8.2 \times 10^{-3}$ & $1.2 \times 10^{-2}$ \\
\hline${ }^{189} \mathrm{Os}$ & 0.9996 & $6.8 \times 10^{-2}$ & $8.3 \times 10^{-4}$ & $6.4 \times 10^{-3}$ & $1.2 \times 10^{-2}$ \\
\hline${ }^{190} \mathrm{Os}$ & 0.9996 & $1.1 \times 10^{-1}$ & $1.4 \times 10^{-3}$ & $4.0 \times 10^{-3}$ & $1.3 \times 10^{-2}$ \\
\hline${ }^{192} \mathrm{Os}$ & 0.9997 & $1.7 \times 10^{-1}$ & $2.3 \times 10^{-3}$ & $9.5 \times 10^{-4}$ & $1.3 \times 10^{-2}$ \\
\hline
\end{tabular}

a) $R$ : Correlation. $b$ ) LOD: Limit of detection $=\frac{3 \times \text { blank standard deviation }}{\text { calibration slope }} c$ ) BEC: Background equivalent concentration $=\frac{\text { calibration intercept }}{\text { calibration slope }}$ 
with an $R^{2}$ value of greater than 0.9996 . The limits of detection (LOD) ranged from $9.5 \times 10^{-4}$ to $2.3 \times 10^{-2} \mathrm{ng} / \mathrm{mL}$. The isotope abundance ratios of ${ }^{186} \mathrm{Os},{ }^{187} \mathrm{Os},{ }^{188} \mathrm{Os},{ }^{189} \mathrm{Os},{ }^{190} \mathrm{Os}$, and ${ }^{192}$ Os were $1.59,1.96,13.24,16.15,26.26$, and $40.78 \%$, respectively. The ascending order of LOD was ${ }^{192} \mathrm{Os}<{ }^{190} \mathrm{Os}$ $<{ }^{189} \mathrm{Os}<{ }^{188} \mathrm{Os}<{ }^{187} \mathrm{Os}<{ }^{186} \mathrm{Os}$, this is in accordance with the isotope abundance ratio of Os. The high abundance ratio of Os leads to the high sensitivity of ICP-MS. The background equivalent concentration (BEC) is the blank value, and the concept of the BEC has been used to evaluate the optimum conditions for analysis. A lower BEC implies the desired signal can be separated more precisely from background noise. The collision gas He was used in this study to reduce the counts from the background. The detected backgrounds were converted to the BEC by dividing the calibration intercept by the calibration slope. The maximum BEC, $2.0 \times 10^{-2} \mathrm{ng} / \mathrm{mL}$, was quite low, which indicates that the collision gas He functioned satisfactorily. These results suggest that the calibration curves of the Os isotopes were successfully achieved.

The Confirmation Test of the Stabilization Solution Work To confirm the effectiveness of the reducing reagents that are expected to reduce osmium tetroxide to normal osmium, we compared them to a liquid in which only neutral salts were dissolved. Sodium chloride, potassium chloride, sodium sulfate, and potassium sulfate were selected, and corresponding solutions were prepared in the same way as the stabilization solutions. Test samples were prepared by adding neutral solutions to a microwave-irradiated solution containing a standard of osmium, and the concentration of each osmium isotope was measured by ICP-MS. The final concentration of the osmium standard was set at $10 \mathrm{ng} / \mathrm{mL}$; this concentration is referred to as the true value with $100 \%$ theoretical recovery. All concentrations of the stabilization solution and neutral solutions were used at $5 \mathrm{~g} / \mathrm{L}$ in this investigation. The results of the spike recovery test are summarized in Table 3. As can be seen, the overestimation of osmium was observed among neutral solutions. However, spike recoveries obtained from the stabilization solutions were consistently in the 70-90\%, which satisfies the 70 to $150 \%$ criteria in USP chapter (233). These results show that reductive reagents, such as ascorbic acid, sodium sulfite, and potassium metabisulfite, can work to alleviate the overestimation of osmium in a similar way

Table 3. Spike Recoveries of Osmium Isotopes Using Stabilization Solutions and Neutral Solutions

\begin{tabular}{|c|c|c|c|c|c|c|}
\hline & \multicolumn{6}{|c|}{ Recovery (\%) } \\
\hline & ${ }^{186} \mathrm{Os}$ & ${ }^{187} \mathrm{Os}$ & ${ }^{188} \mathrm{Os}$ & ${ }^{189} \mathrm{Os}$ & ${ }^{190} \mathrm{Os}$ & ${ }^{192}$ Os \\
\hline Without any solutions & 258 & 261 & 259 & 252 & 256 & 264 \\
\hline Sodium chloride $5.0 \mathrm{~g} / \mathrm{L}$ & 240 & 241 & 234 & 231 & 231 & 232 \\
\hline Potassium chloride $5.0 \mathrm{~g} / \mathrm{L}$ & 254 & 255 & 247 & 244 & 242 & 245 \\
\hline Sodium sulfate $5.0 \mathrm{~g} / \mathrm{L}$ & 254 & 252 & 244 & 241 & 239 & 245 \\
\hline Potassium sulfate $5.0 \mathrm{~g} / \mathrm{L}$ & 275 & 264 & 256 & 254 & 252 & 259 \\
\hline Thiourea $5.0 \mathrm{~g} / \mathrm{L}$ & 81 & 81 & 83 & 79 & 78 & 79 \\
\hline Ascorbic acid $5.0 \mathrm{~g} / \mathrm{L}$ & 80 & 79 & 79 & 77 & 76 & 77 \\
\hline Sodium sulfite $5.0 \mathrm{~g} / \mathrm{L}$ & 85 & 85 & 83 & 81 & 80 & 81 \\
\hline Potassium metabisulfite $5.0 \mathrm{~g} / \mathrm{L}$ & 90 & 93 & 90 & 86 & 86 & 87 \\
\hline
\end{tabular}

Table 4. Spike Recoveries of Osmium Isotopes Using Various Stabilization Solutions

\begin{tabular}{|c|c|c|c|c|c|c|}
\hline & \multicolumn{6}{|c|}{ Recovery (\%) } \\
\hline & ${ }^{186} \mathrm{Os}$ & ${ }^{187} \mathrm{Os}$ & ${ }^{188} \mathrm{Os}$ & ${ }^{189} \mathrm{Os}$ & ${ }^{190} \mathrm{Os}$ & ${ }^{192} \mathrm{Os}$ \\
\hline Thiourea $10 \mathrm{~g} / \mathrm{L}$ & 97 & 96 & 96 & 92 & 91 & 93 \\
\hline Thiourea $7.5 \mathrm{~g} / \mathrm{L}$ & 81 & 82 & 81 & 78 & 77 & 79 \\
\hline Thiourea $5.0 \mathrm{~g} / \mathrm{L}$ & 81 & 81 & 83 & 79 & 78 & 79 \\
\hline Thiourea $2.5 \mathrm{~g} / \mathrm{L}$ & 82 & 82 & 82 & 79 & 77 & 79 \\
\hline Thiourea $1.0 \mathrm{~g} / \mathrm{L}$ & 80 & 80 & 80 & 77 & 76 & 77 \\
\hline Ascorbic acid $10 \mathrm{~g} / \mathrm{L}$ & 78 & 78 & 78 & 75 & 74 & 75 \\
\hline Ascorbic acid $7.5 \mathrm{~g} / \mathrm{L}$ & 77 & 77 & 78 & 75 & 74 & 75 \\
\hline Ascorbic acid $5.0 \mathrm{~g} / \mathrm{L}$ & 80 & 79 & 79 & 77 & 76 & 77 \\
\hline Ascorbic acid $2.5 \mathrm{~g} / \mathrm{L}$ & 81 & 82 & 81 & 79 & 78 & 78 \\
\hline Ascorbic acid $1.0 \mathrm{~g} / \mathrm{L}$ & 78 & 76 & 76 & 74 & 73 & 74 \\
\hline Sodium sulfite $10 \mathrm{~g} / \mathrm{L}$ & 83 & 82 & 80 & 78 & 77 & 77 \\
\hline Sodium sulfite $7.5 \mathrm{~g} / \mathrm{L}$ & 79 & 81 & 79 & 78 & 76 & 76 \\
\hline Sodium sulfite $5.0 \mathrm{~g} / \mathrm{L}$ & 85 & 85 & 83 & 81 & 80 & 81 \\
\hline Sodium sulfite $2.5 \mathrm{~g} / \mathrm{L}$ & 96 & 94 & 95 & 92 & 91 & 92 \\
\hline Sodium sulfite $1.0 \mathrm{~g} / \mathrm{L}$ & 158 & 157 & 157 & 152 & 150 & 151 \\
\hline Potassium metabisulfite $10 \mathrm{~g} / \mathrm{L}$ & 109 & 112 & 107 & 102 & 102 & 102 \\
\hline Potassium metabisulfite $7.5 \mathrm{~g} / \mathrm{L}$ & 91 & 92 & 89 & 87 & 86 & 87 \\
\hline Potassium metabisulfite $5.0 \mathrm{~g} / \mathrm{L}$ & 90 & 93 & 90 & 86 & 86 & 87 \\
\hline Potassium metabisulfite $2.5 \mathrm{~g} / \mathrm{L}$ & 96 & 95 & 95 & 92 & 90 & 92 \\
\hline Potassium metabisulfite $1.0 \mathrm{~g} / \mathrm{L}$ & 142 & 143 & 143 & 137 & 137 & 139 \\
\hline
\end{tabular}


to thiourea. In the following experiments, thiourea, ascorbic acid, sodium sulfite, and potassium metabisulfite were taken forward and other parameters were investigated.

The Effects of Concentrations of Stabilization Solutions on the Recovery of Osmium Isotopes The effects of concentration of four stabilization solutions, namely thiourea, ascorbic acid, sodium sulfite, and potassium metabisulfite, on recoveries of osmium isotopes were compared at five indicated concentrations by a spike recovery test. A summary of the recoveries of osmium isotopes is shown in Table 4. The recoveries obtained by using the thiourea stabilization solution were determined to be from 76 to $97 \%$ of the true value at all concentrations tested. Considering that the accuracy is defined to be within 70 to $150 \%$ of the true value in USP chapter (233), these recoveries met the requirement of the acceptance criteria. In the case of ascorbic acid, the recovery rates were from 73 to $82 \%$, and these results meet the acceptance criteria at the same concentration range as that of thiourea. When sodium sulfite was tested for recovery of osmium isotopes, recovery rates were found to be from 76 to $96 \%$ at the concentrations from 2.5 to $10 \mathrm{~g} / \mathrm{L}$, which satisfies the acceptance criteria defined in USP chapter (233). However, at the concentration of $1.0 \mathrm{~g} / \mathrm{L}$ sodium sulfite solution, some of the recoveries were overestimated (150 to $158 \%$ ), indicating that sodium sulfite could not work as a stabilization solution at this concentration. These results suggest that sodium sulfite stabilization solution can be considered as a useful stabilization solution at concentrations ranging from 2.5 to $10 \mathrm{~g} / \mathrm{L}$. Potassium metabisulfite showed re-

Table 5. Summary of Spike Recoveries and RSDs for Each Stabilization Solution

\begin{tabular}{|c|c|c|c|c|c|c|}
\hline & ${ }^{186} \mathrm{Os}$ & ${ }^{187} \mathrm{Os}$ & ${ }^{188} \mathrm{Os}$ & ${ }^{189} \mathrm{Os}$ & ${ }^{190} \mathrm{Os}$ & ${ }^{192} \mathrm{Os}$ \\
\hline \multirow{6}{*}{$\begin{array}{l}\text { Thiourea } 1.0 \mathrm{~g} / \mathrm{L} \\
\text { Recovery }(\%)\end{array}$} & 87 & 89 & 84 & 83 & 84 & 85 \\
\hline & 84 & 85 & 82 & 81 & 82 & 82 \\
\hline & 84 & 83 & 80 & 79 & 80 & 81 \\
\hline & 88 & 89 & 86 & 85 & 86 & 86 \\
\hline & 83 & 82 & 79 & 78 & 79 & 80 \\
\hline & 83 & 84 & 81 & 81 & 81 & 81 \\
\hline Average recovery & 85 & 85 & 82 & 81 & 82 & 83 \\
\hline Standard deviation & 2.0 & 3.0 & 2.6 & 2.5 & 2.6 & 2.4 \\
\hline RSD (\%) & 2.3 & 3.5 & 3.2 & 3.1 & 3.2 & 3.0 \\
\hline \multirow{6}{*}{$\begin{array}{l}\text { Ascorbic acid } 1.0 \mathrm{~g} / \mathrm{L} \\
\text { Recovery (\%) }\end{array}$} & 95 & 95 & 92 & 91 & 92 & 93 \\
\hline & 109 & 109 & 104 & 102 & 102 & 104 \\
\hline & 98 & 98 & 95 & 95 & 95 & 96 \\
\hline & 100 & 98 & 96 & 95 & 95 & 97 \\
\hline & 95 & 97 & 94 & 93 & 93 & 95 \\
\hline & 96 & 98 & 95 & 94 & 93 & 96 \\
\hline Average recovery & 99 & 99 & 96 & 95 & 95 & 97 \\
\hline Standard deviation & 5.1 & 4.9 & 4.0 & 3.7 & 3.8 & 3.8 \\
\hline RSD (\%) & 5.2 & 5.0 & 4.2 & 3.9 & 4.0 & 4.0 \\
\hline \multirow{6}{*}{$\begin{array}{l}\text { Sodium sulfite } 2.5 \mathrm{~g} / \mathrm{L} \\
\text { Recovery }(\%)\end{array}$} & 118 & 117 & 113 & 114 & 114 & 115 \\
\hline & 120 & 119 & 116 & 116 & 116 & 118 \\
\hline & 110 & 113 & 109 & 108 & 109 & 110 \\
\hline & 117 & 117 & 111 & 110 & 112 & 112 \\
\hline & 109 & 110 & 106 & 105 & 106 & 107 \\
\hline & 100 & 99 & 97 & 95 & 97 & 97 \\
\hline Average recovery & 112 & 112 & 109 & 108 & 109 & 110 \\
\hline Standard deviation & 7.3 & 7.3 & 6.9 & 7.2 & 7.0 & 7.1 \\
\hline RSD (\%) & 6.5 & 6.5 & 6.3 & 6.7 & 6.4 & 6.5 \\
\hline \multirow{6}{*}{$\begin{array}{l}\text { Potassium metabisulfite } 2.5 \mathrm{~g} / \mathrm{L} \\
\text { Recovery }(\%)\end{array}$} & 96 & 96 & 92 & 91 & 92 & 93 \\
\hline & 95 & 97 & 93 & 91 & 92 & 93 \\
\hline & 88 & 87 & 84 & 84 & 84 & 85 \\
\hline & 92 & 90 & 87 & 86 & 87 & 88 \\
\hline & 90 & 89 & 86 & 85 & 86 & 86 \\
\hline & 85 & 85 & 82 & 81 & 82 & 82 \\
\hline Average recovery & 91 & 91 & 87 & 86 & 87 & 88 \\
\hline Standard deviation & 4.2 & 5.0 & 4.2 & 4.0 & 4.2 & 4.5 \\
\hline RSD (\%) & 4.6 & 5.5 & 4.8 & 4.7 & 4.9 & 5.1 \\
\hline
\end{tabular}


Table 6. Spike Recoveries of Osmium Isotopes in Low Concentration Solutions of Thiourea and Ascorbic Acid

\begin{tabular}{|c|c|c|c|c|c|c|}
\hline & \multicolumn{6}{|c|}{ Recovery $(\%)$} \\
\hline & ${ }^{186} \mathrm{Os}$ & ${ }^{187} \mathrm{Os}$ & ${ }^{188} \mathrm{Os}$ & ${ }^{189} \mathrm{Os}$ & ${ }^{190} \mathrm{Os}$ & ${ }^{192} \mathrm{Os}$ \\
\hline Thiourea $0.1 \mathrm{~g} / \mathrm{L}$ & 76 & 76 & 73 & 73 & 72 & 74 \\
\hline Thiourea $0.01 \mathrm{~g} / \mathrm{L}$ & 126 & 128 & 123 & 122 & 122 & 125 \\
\hline Thiourea $0.001 \mathrm{~g} / \mathrm{L}$ & 247 & 249 & 244 & 240 & 250 & 255 \\
\hline Ascorbic acid $0.1 \mathrm{~g} / \mathrm{L}$ & 249 & 250 & 241 & 244 & 251 & 254 \\
\hline Ascorbic acid $0.01 \mathrm{~g} / \mathrm{L}$ & 246 & 245 & 237 & 241 & 251 & 249 \\
\hline Ascorbic acid $0.001 \mathrm{~g} / \mathrm{L}$ & 251 & 253 & 244 & 247 & 256 & 256 \\
\hline
\end{tabular}

coveries from 86 to $112 \%$ at concentrations from 2.5 to $10 \mathrm{~g} / \mathrm{L}$. These results were similar to those of sodium sulfite. Although all spike recoveries at five concentrations of potassium metabisulfite were within the acceptable range defined in USP (233), the values of each osmium isotope obtained at the concentration of $1.0 \mathrm{~g} / \mathrm{L}$ were very close to the spike recovery maximum limit $(150 \%)$. These results suggest that the potassium metabisulfite stabilization solution works effectively as a stabilization solution at concentrations ranging from 2.5 to $10 \mathrm{~g} / \mathrm{L}$.

Evaluation of Accuracy and Precision of Spike Recoveries of Osmium Isotopes Quantitative and repeated analyses were performed for spike recoveries of osmium isotopes under treatment with stabilization solutions. Thiourea, ascorbic acid, sodium sulfite and potassium metabisulfite were used at 1.0, $1.0,2.5$ and $2.5 \mathrm{~g} / \mathrm{L}$, respectively. Table 5 shows the summary of recovery rates of osmium isotopes with six replicates for each sample. All recoveries were in the range of 70 to $150 \%$, and RSDs of recoveries in each stabilization solution were less than $3.5 \%$ in thiourea, $5.2 \%$ in ascorbic acid, $6.7 \%$ in sodium sulfite, and $5.5 \%$ in potassium metabisulfite. These results met the precision requirement (RSD $\leq 20 \%$ ) of USP (233). Although the highest sensitivity $\mathrm{m} / \mathrm{z}$ number was ${ }^{192}$ Os - obtained from calibration curve results - there was no significant difference in the average recovery among all Os isotopes. Therefore, all Os isotopes could be selected for Os determination. The reproducibility evaluation requires repeat analysis on a different day, using a different instrument, operation by a different analyst, or a combination of these. The obtained results are then combined with the first precision test results. We carried out the same analysis on a subsequent day and the results are summarized in the supplementary material (Supplementary Table 1 and Supplementary Table 2). The RSDs obtained for 12 analyses in each stabilization solution were less than $3.3 \%$ in thiourea, $12.7 \%$ in ascorbic acid, $9.0 \%$ in sodium sulfite, and $10.6 \%$ in potassium metabisulfite. These results meet the precision requirement ( $\mathrm{RSD} \leq 25 \%$ ).

Verification of Minimum Effective Concentration to Stabilize Osmium Considering the results in Table 4, we believe that thiourea and ascorbic acid could work as stabilization solutions at concentrations lower than $1.0 \mathrm{~g} / \mathrm{L}$. We sought to determine the lowest effective concentration of thiourea and ascorbic acid to stabilize the osmium in spike recovery tests. The concentrations were used in ten-fold serial dilutions, and the results are shown in Table 6 . Thiourea at $0.1 \mathrm{~g} / \mathrm{L}$ showed remarkable effectiveness with recovery rates of osmium isotopes from 72 to $76 \%$, which was very similar to the results achieved by $1.0 \mathrm{~g} / \mathrm{L}$ thiourea. A ten-fold diluted concentration of $0.1 \mathrm{~g} / \mathrm{L}$ thiourea was less effective with recovery rates from 122 to $128 \%$; however, such recovery rates still meet the acceptance criteria defined in USP chapter (233). Thiourea at $0.001 \mathrm{~g} / \mathrm{L}$ showed no effect on recovery rates. These results suggest that the minimum effective concentration of thiourea is $0.1 \mathrm{~g} / \mathrm{L}$. In the ascorbic acid tests, none of the recovery rates met the acceptance criteria at the concentrations tested. Considering the results shown in Tables 4 and 6, the minimum effective concentration of ascorbic acid to stabilize osmium seems to be $1.0 \mathrm{~g} / \mathrm{L}$.

Investigation of Stabilization Solutions in a Digested Tablet Matrix The efficiency of stabilization solutions was investigated in a digested tablet matrix to assess whether those solutions can prevent the overestimation of osmium isotopes in the presence of drugs. Pravastatin sodium tablets and doxazosin mesylate tablets were digested with the same amount of osmium as before, and then stabilization solutions were added to the digested solutions before ICP-MS analysis. Stabilization solutions were used at the same concentrations as those in Table 4. Table 7 shows the results of the spike recovery rates of osmium isotopes in the digested pravastatin sodium matrix. All recovery rates were from 93 to $117 \%$ when thiourea was used, which satisfied the acceptance criteria. Ascorbic acid at concentrations more than $1.0 \mathrm{~g} / \mathrm{L}$ showed equivalent efficacy to that obtained by thiourea. Ascorbic acid at $1.0 \mathrm{~g} / \mathrm{L}$ showed recovery rates that slightly exceeded the maximum threshold of $150 \%$. These results indicate that ascorbic acid works as a stabilization solution at $2.5 \mathrm{~g} / \mathrm{L}$ or more in a matrix of digested pravastatin sodium tablets. Sodium sulfite and potassium metabisulfite behaved along the same lines, and the recovery rates met the acceptance requirement levels at higher range concentrations $(5.0-10 \mathrm{~g} / \mathrm{L})$. Lower range concentrations $(2.5-1.0 \mathrm{~g} / \mathrm{L})$ gave marginal effects and did not meet the acceptance criteria.

To extend the knowledge about the efficacy of stabilization solutions in drug matrices, an evaluation of the stabilization solutions in a matrix of digested doxazosin mesylate tablets was carried out. The results are summarized in Table 8 . Regarding thiourea, all the recovery rates ranged from 82 to $105 \%$ and met the acceptance criteria. Ascorbic acid exhibited recovery rates from 84 to $101 \%$, which was equivalent to those of thiourea. Sodium sulfite and potassium metabisulfite clearly achieved the acceptable criteria at more than $7.5 \mathrm{~g} / \mathrm{L}$, whereas they did not show as much efficacy as that observed in the case of pravastatin sodium tablets matrix at less than $5.0 \mathrm{~g} / \mathrm{L}$. Compared with the results obtained in a matrix of digested pravastatin sodium tablets, thiourea and ascorbic acid showed equivalent or more effectiveness in the digested doxazosin mesylate tablet matrix whereas sodium sulfite and potassium metabisulfite were less effective in the same matrix. Although the reason for the different activities of stabilizing solutions under those two matrices is unclear, it may be caused by the different levels of total dissolved ions in each tablet diges- 
Table 7. Spike Recoveries of Osmium Isotopes Using Each Stabilization Solution in Microwave-Digested Pravastatin Sodium Tablets

\begin{tabular}{|c|c|c|c|c|c|c|}
\hline & \multicolumn{6}{|c|}{ Recovery (\%) } \\
\hline & ${ }^{186} \mathrm{Os}$ & ${ }^{187} \mathrm{Os}$ & ${ }^{188} \mathrm{Os}$ & ${ }^{189} \mathrm{Os}$ & ${ }^{190} \mathrm{Os}$ & ${ }^{192} \mathrm{Os}$ \\
\hline Thiourea $10 \mathrm{~g} / \mathrm{L}$ & 108 & 104 & 103 & 102 & 101 & 102 \\
\hline Thiourea $7.5 \mathrm{~g} / \mathrm{L}$ & 112 & 110 & 107 & 106 & 104 & 106 \\
\hline Thiourea $5.0 \mathrm{~g} / \mathrm{L}$ & 102 & 100 & 98 & 96 & 95 & 96 \\
\hline Thiourea $2.5 \mathrm{~g} / \mathrm{L}$ & 99 & 99 & 94 & 93 & 93 & 93 \\
\hline Thiourea $1.0 \mathrm{~g} / \mathrm{L}$ & 117 & 113 & 111 & 109 & 108 & 109 \\
\hline Ascorbic acid $10 \mathrm{~g} / \mathrm{L}$ & 86 & 83 & 81 & 81 & 81 & 81 \\
\hline Ascorbic acid $7.5 \mathrm{~g} / \mathrm{L}$ & 85 & 82 & 79 & 80 & 79 & 80 \\
\hline Ascorbic acid $5.0 \mathrm{~g} / \mathrm{L}$ & 92 & 94 & 87 & 88 & 87 & 89 \\
\hline Ascorbic acid $2.5 \mathrm{~g} / \mathrm{L}$ & 105 & 100 & 98 & 99 & 98 & 99 \\
\hline Ascorbic acid $1.0 \mathrm{~g} / \mathrm{L}$ & 164 & 163 & 157 & 157 & 156 & 162 \\
\hline Sodium sulfite $10 \mathrm{~g} / \mathrm{L}$ & 81 & 80 & 76 & 76 & 75 & 75 \\
\hline Sodium sulfite $7.5 \mathrm{~g} / \mathrm{L}$ & 82 & 76 & 74 & 75 & 74 & 74 \\
\hline Sodium sulfite $5.0 \mathrm{~g} / \mathrm{L}$ & 85 & 82 & 80 & 80 & 79 & 79 \\
\hline Sodium sulfite $2.5 \mathrm{~g} / \mathrm{L}$ & 190 & 187 & 181 & 182 & 182 & 186 \\
\hline Sodium sulfite $1.0 \mathrm{~g} / \mathrm{L}$ & 190 & 187 & 180 & 181 & 181 & 189 \\
\hline Potassium metabisulfite $10 \mathrm{~g} / \mathrm{L}$ & 84 & 80 & 78 & 79 & 77 & 79 \\
\hline Potassium metabisulfite $7.5 \mathrm{~g} / \mathrm{L}$ & 80 & 78 & 74 & 76 & 75 & 76 \\
\hline Potassium metabisulfite $5.0 \mathrm{~g} / \mathrm{L}$ & 107 & 105 & 103 & 102 & 102 & 104 \\
\hline Potassium metabisulfite $2.5 \mathrm{~g} / \mathrm{L}$ & 150 & 151 & 145 & 145 & 145 & 148 \\
\hline Potassium metabisulfite $1.0 \mathrm{~g} / \mathrm{L}$ & 160 & 156 & 152 & 153 & 151 & 158 \\
\hline Without stabilization solution & 179 & 182 & 174 & 174 & 175 & 185 \\
\hline
\end{tabular}

Table 8. Spike Recoveries of Osmium Isotopes Using Each Stabilization Solution in Microwave-Digested Doxazosin Mesylate Tablets

\begin{tabular}{|c|c|c|c|c|c|c|}
\hline & \multicolumn{6}{|c|}{ Recovery (\%) } \\
\hline & ${ }^{186} \mathrm{Os}$ & ${ }^{187} \mathrm{Os}$ & ${ }^{188} \mathrm{Os}$ & ${ }^{189} \mathrm{Os}$ & ${ }^{190} \mathrm{Os}$ & ${ }^{192} \mathrm{Os}$ \\
\hline Thiourea $10 \mathrm{~g} / \mathrm{L}$ & 105 & 103 & 99 & 100 & 100 & 100 \\
\hline Thiourea $7.5 \mathrm{~g} / \mathrm{L}$ & 94 & 93 & 90 & 91 & 91 & 91 \\
\hline Thiourea $5.0 \mathrm{~g} / \mathrm{L}$ & 102 & 100 & 98 & 99 & 99 & 99 \\
\hline Thiourea $2.5 \mathrm{~g} / \mathrm{L}$ & 82 & 83 & 82 & 82 & 83 & 82 \\
\hline Thiourea $1.0 \mathrm{~g} / \mathrm{L}$ & 87 & 85 & 83 & 84 & 84 & 84 \\
\hline Ascorbic acid $10 \mathrm{~g} / \mathrm{L}$ & 89 & 87 & 85 & 84 & 85 & 85 \\
\hline Ascorbic acid $7.5 \mathrm{~g} / \mathrm{L}$ & 89 & 88 & 84 & 84 & 85 & 86 \\
\hline Ascorbic acid $5.0 \mathrm{~g} / \mathrm{L}$ & 98 & 101 & 97 & 96 & 97 & 97 \\
\hline Ascorbic acid $2.5 \mathrm{~g} / \mathrm{L}$ & 89 & 90 & 86 & 86 & 87 & 87 \\
\hline Ascorbic acid $1.0 \mathrm{~g} / \mathrm{L}$ & 100 & 100 & 97 & 96 & 97 & 97 \\
\hline Sodium sulfite $10 \mathrm{~g} / \mathrm{L}$ & 80 & 80 & 78 & 78 & 76 & 78 \\
\hline Sodium sulfite $7.5 \mathrm{~g} / \mathrm{L}$ & 113 & 111 & 109 & 107 & 107 & 109 \\
\hline Sodium sulfite $5.0 \mathrm{~g} / \mathrm{L}$ & 141 & 139 & 136 & 134 & 133 & 135 \\
\hline Sodium sulfite $2.5 \mathrm{~g} / \mathrm{L}$ & 151 & 150 & 147 & 144 & 145 & 146 \\
\hline Sodium sulfite $1.0 \mathrm{~g} / \mathrm{L}$ & 161 & 158 & 155 & 154 & 153 & 155 \\
\hline Potassium metabisulfite $10 \mathrm{~g} / \mathrm{L}$ & 80 & 77 & 76 & 74 & 75 & 75 \\
\hline Potassium metabisulfite $7.5 \mathrm{~g} / \mathrm{L}$ & 113 & 110 & 106 & 105 & 105 & 106 \\
\hline Potassium metabisulfite $5.0 \mathrm{~g} / \mathrm{L}$ & 143 & 141 & 135 & 136 & 135 & 136 \\
\hline Potassium metabisulfite $2.5 \mathrm{~g} / \mathrm{L}$ & 160 & 162 & 155 & 153 & 154 & 155 \\
\hline Potassium metabisulfite $1.0 \mathrm{~g} / \mathrm{L}$ & 168 & 168 & 161 & 160 & 160 & 161 \\
\hline Without stabilization solution & 179 & 179 & 172 & 172 & 174 & 181 \\
\hline
\end{tabular}

tion matrix. For example, the concentration of aluminum was roughly estimated from its signal intensity obtained by ICP-MS, and the values were 500000 and $50 \mathrm{ppb}$ for pravastatin sodium tablet digestion and doxazosin mesylate tablet digestion, respectively. The density of inorganic ions in solution influences the nebulization performance and ionization efficiency. Therefore, the activities of the stabilizing solutions were different for digested pravastatin sodium tablet matrix and digested doxazosin mesylate tablet matrix. This consideration needs to be further investigated.

Simultaneous Determination of All Elements Defined by the ICH-Q3D Guidelines in a Digested Tablet Matrix It is necessary to confirm whether the addition of stabilization solution influences the detection of other elements defined by the ICH-Q3D guidelines when they are evaluated simultaneously. The stabilization solutions were applied for a model 
Table 9. Setup Conditions for Measurement of All Elements Defined by the ICH-Q3D Guidelines

\begin{tabular}{|c|c|c|c|c|c|c|c|}
\hline \multirow{2}{*}{ Element } & \multirow{2}{*}{$\begin{array}{l}\text { Mass-to-charge ratio } \\
\qquad(\mathrm{m} / \mathrm{z})\end{array}$} & \multirow{2}{*}{ Internal standard } & \multirow{2}{*}{ Collision gas } & \multicolumn{4}{|c|}{ Calibration levels (ng/mL) } \\
\hline & & & & $1(0 J)$ & $2(0.5 J)$ & $3(1 J)$ & $4(1.5 J)$ \\
\hline $\mathrm{Li}$ & 7 & ${ }^{209} \mathrm{Bi}$ & $\mathrm{He}$ & 0 & 27.5 & 55 & 82.5 \\
\hline $\mathrm{V}$ & 51 & ${ }^{209} \mathrm{Bi}$ & $\mathrm{He}$ & 0 & 5 & 10 & 15 \\
\hline $\mathrm{Cr}$ & 52 & ${ }^{209} \mathrm{Bi}$ & $\mathrm{He}$ & 0 & 550 & 1100 & 1650 \\
\hline Co & 59 & ${ }^{209} \mathrm{Bi}$ & $\mathrm{He}$ & 0 & 2.5 & 5 & 7.5 \\
\hline $\mathrm{Ni}$ & 60 & ${ }^{209} \mathrm{Bi}$ & $\mathrm{He}$ & 0 & 10 & 20 & 30 \\
\hline $\mathrm{Cu}$ & 63 & ${ }^{209} \mathrm{Bi}$ & $\mathrm{He}$ & 0 & 150 & 300 & 450 \\
\hline As & 75 & ${ }^{209} \mathrm{Bi}$ & $\mathrm{He}$ & 0 & 0.75 & 1.5 & 2.25 \\
\hline $\mathrm{Se}$ & 78 & ${ }^{209} \mathrm{Bi}$ & $\mathrm{He}$ & 0 & 7.5 & 15 & 22.5 \\
\hline Mo & 95 & ${ }^{209} \mathrm{Bi}$ & $\mathrm{He}$ & 0 & 150 & 300 & 450 \\
\hline $\mathrm{Ru}$ & 101 & ${ }^{209} \mathrm{Bi}$ & $\mathrm{He}$ & 0 & 5 & 10 & 15 \\
\hline $\mathrm{Rh}$ & 103 & ${ }^{209} \mathrm{Bi}$ & $\mathrm{He}$ & 0 & 5 & 10 & 15 \\
\hline $\mathrm{Pd}$ & 105 & ${ }^{209} \mathrm{Bi}$ & $\mathrm{He}$ & 0 & 5 & 10 & 15 \\
\hline $\mathrm{Ag}$ & 107 & ${ }^{209} \mathrm{Bi}$ & $\mathrm{He}$ & 0 & 7.5 & 15 & 22.5 \\
\hline $\mathrm{Cd}$ & 111 & ${ }^{209} \mathrm{Bi}$ & $\mathrm{He}$ & 0 & 0.25 & 0.5 & 0.75 \\
\hline $\mathrm{Sn}$ & 118 & ${ }^{209} \mathrm{Bi}$ & $\mathrm{He}$ & 0 & 300 & 600 & 900 \\
\hline $\mathrm{Sb}$ & 121 & ${ }^{209} \mathrm{Bi}$ & $\mathrm{He}$ & 0 & 60 & 120 & 180 \\
\hline $\mathrm{Ba}$ & 137 & ${ }^{209} \mathrm{Bi}$ & $\mathrm{He}$ & 0 & 70 & 140 & 210 \\
\hline Os & 189 & ${ }^{209} \mathrm{Bi}$ & $\mathrm{He}$ & 0 & 5 & 10 & 15 \\
\hline Ir & 193 & ${ }^{209} \mathrm{Bi}$ & $\mathrm{He}$ & 0 & 5 & 10 & 15 \\
\hline $\mathrm{Pt}$ & 195 & ${ }^{209} \mathrm{Bi}$ & $\mathrm{He}$ & 0 & 5 & 10 & 15 \\
\hline $\mathrm{Au}$ & 197 & ${ }^{209} \mathrm{Bi}$ & $\mathrm{He}$ & 0 & 5 & 10 & 15 \\
\hline $\mathrm{Hg}$ & 201 & ${ }^{209} \mathrm{Bi}$ & $\mathrm{He}$ & 0 & 1.5 & 3 & 4.5 \\
\hline $\mathrm{Tl}$ & 205 & ${ }^{209} \mathrm{Bi}$ & $\mathrm{He}$ & 0 & 0.4 & 0.8 & 1.2 \\
\hline $\mathrm{Pb}$ & 208 & ${ }^{209} \mathrm{Bi}$ & $\mathrm{He}$ & 0 & 0.25 & 0.5 & 0.75 \\
\hline
\end{tabular}
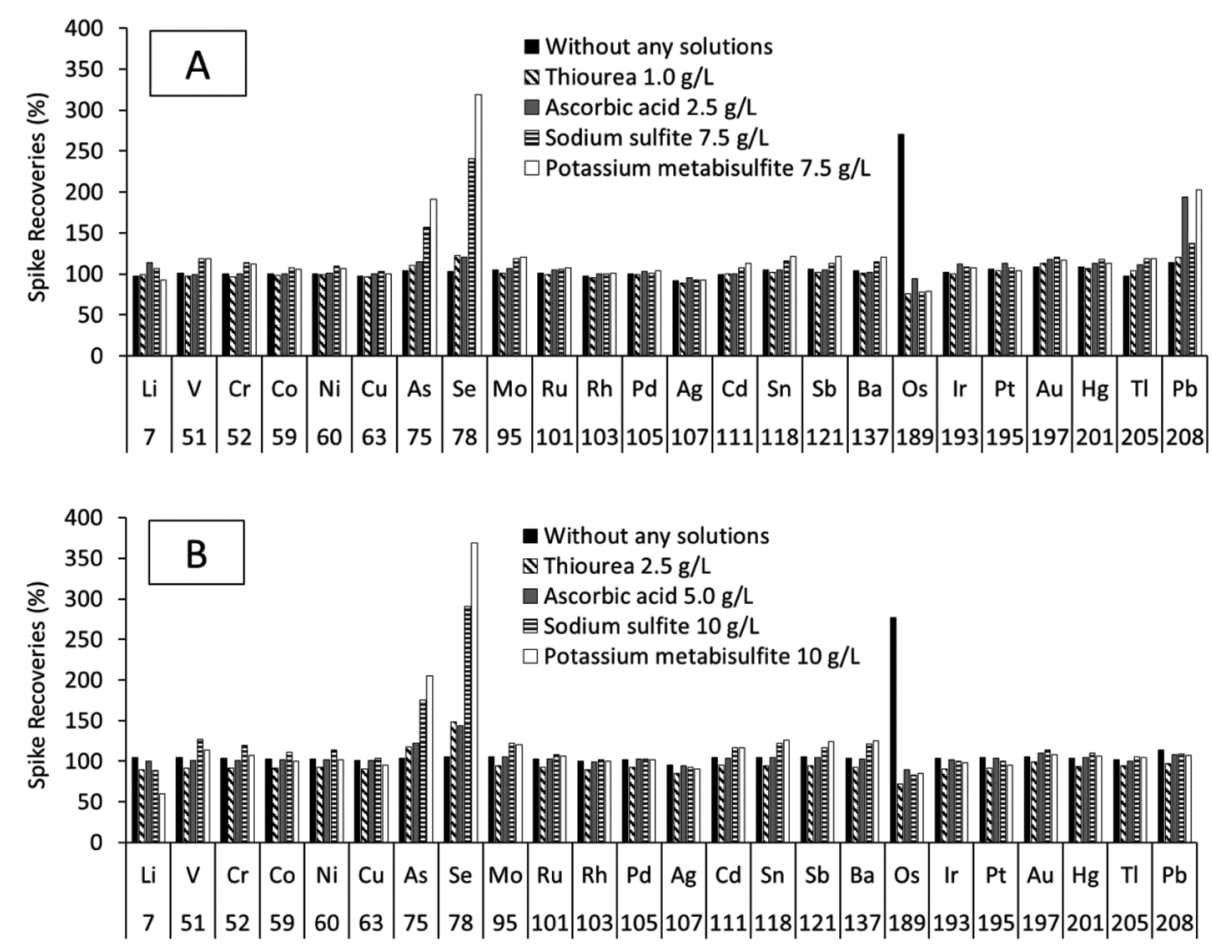

Fig. 3. Spike Recoveries of All Elements Defined by the ICH-Q3D Guidelines Using Each Stabilization Solution in Microwave-Digested Pravastatin Sodium Tablets (A) and Doxazosin Mesylate Tablets (B) (the Actual Values of Each Spike Recovery Are Summarized in Supplementary Table 3 and Supplementary Table 4.)

representative situation. To carry out the spike recovery test, target concentrations of each element must be calculated. The target concentrations are known as $J$ vales $(\mathrm{ng} / \mathrm{mL})$ and are determined based on the PDEs, maximum daily dose of drug, and the dilution rate of the sample preparation. In cases where the daily maximum dose was less than $10 \mathrm{~g} / \mathrm{d}$, all PDEs could be divided by ten, then the limit of concentration for the drug $(\mu \mathrm{g} / \mathrm{g})$ could be obtained. The average weights of a pravastatin 
sodium tablet and doxazosin mesylate tablet are 0.085 and $0.12 \mathrm{~g}$, respectively. To calculate the $J$ values in an easy-tounderstand way, it was assumed that $0.1 \mathrm{~g}$ sample was digested and diluted to $100 \mathrm{~mL}$. For example, the PDE of cadmium $(\mathrm{Cd})$ is $5 \mu \mathrm{g} / \mathrm{d}$, which is divided by 10 , to give a $\mathrm{Cd}$ concentration limit for drugs of $0.5 \mu \mathrm{g} / \mathrm{g}$. Then the dilution rate of sample must be considered. If the $0.1 \mathrm{~g}$ sample was digested and diluted in a $100 \mathrm{~mL}$ volumetric flask, the target $J$ value of Cd is calculated to be $0.5 \mathrm{ng} / \mathrm{mL}(0.5 \mu \mathrm{g} / \mathrm{g} \times 0.1 \mathrm{~g} / 100 \mathrm{~mL})$. The calibration curves were obtained by taking measurements of a blank $(0 J), 0.5 J, 1 J$, and $1.5 J$ samples. Spiked samples were prepared to set the final concentration $J$ values. All $J$ values and other conditions are summarized in Table 9. Figure 3 shows the effects of the stabilization solutions on the determination of the other elements. The added amounts of stabilization solution are indicated in Fig. 3. In the no-stabilization-solution case, the recovery rates of all elements were around $100 \%$ except for Os. When the stabilization solutions were added, the Os recoveries were in the range $70-150 \%$, but some elements, such as $\mathrm{As}, \mathrm{Se}$, and $\mathrm{Pb}$, did not meet the criteria. As and $\mathrm{Se}$ are well known to have low ionization rates in high-energy argon plasma consisting of electrons and positively charged argon ions. The addition of stabilization solution makes As and Se much more unstable and prone to ionization. The sensitivity of ICPMS therefore became inaccurate and did not meet the criteria. The target value for $\mathrm{Pb}$ is an exceedingly low concentration of $0.5 \mathrm{ng} / \mathrm{mL}$. Adding stabilization solution critically affected the measurement error and led to irregular spike recovery.

The results show that it is better to carry out two separate steps. All elements in the ICH-Q3D guidelines except Os could be determined with no stabilization solution. In cases where Os concentration must be determined, the stabilization solution method should be employed.

\section{Conclusion}

This study revealed that all tested reagents - thiourea, ascorbic acid, sodium sulfite, and potassium metabisulfite-work as stabilizers for osmium isotopes in microwave-irradiated acid digestion and ICP-MS analysis. Furthermore, these procedures meet the acceptance criteria defined in USP chapter (233) for accuracy (spike recoveries 70 to $150 \%$ ) and precision (RSD $\leq 20 \%$ ). The minimum effective concentrations of stabilization solutions for $10 \mathrm{ng} / \mathrm{mL}$ osmium were $1.0 \mathrm{~g} / \mathrm{L}$ of thiourea and ascorbic acid, $2.5 \mathrm{~g} / \mathrm{L}$ of sodium sulfite and potassium metabisulfite in blank matrix. Thiourea was clearly applicable for a real situation at all levels. This may be because making a complex interaction between thiourea and osmium to stabilize osmium may be a more effective strategy than using reductive reagents. Although thiourea and ascorbic acid showed better performance in this research, it is an organic compound that might cause soot to accumulate near the plasma generation. In contrast, the generation of soot is not a concern if inorganic compounds, sodium sulfite and potassium metabisulfite, are used. Adding stabilization solutions influenced the determination of other elements defined by the ICH-Q3D guidelines. It is therefore better to carry out Os determination independently. Preventing overestimation and achieving highly accurate and precise osmium recoveries are important for evaluating the quality of drug products and substances. Further studies on the stabilization mechanism and spike recovery tests in pharmaceuticals of these agents are needed to develop a reliable method for osmium determination.
Acknowledgments The authors would like to express our sincere thanks to the member of Toyama Prefectural Institute for Pharmaceutical Research for helpful discussions. The authors also sincerely thank Toyama Prefecture and Toyama Pharmaceutical Research Association for their research support. We thank James Murray, Ph.D. for editing a draft of this manuscript.

Conflict of Interest The authors declare no conflict of interest.

Supplementary Materials The online version of this article contains supplementary materials.

\section{References}

1) Matsuhama M., Saito R., Miyazaki S., Chem. Pharm. Bull., 68, 1034-1048 (2020).

2) The United States Pharmacopeial Convention, "USP(232) Elemental Impurities-Limits. Forum,” Vol. 42, 2017, pp. 8065-8069.

3) The United States Pharmacopeial Convention, "USP(233) Elemental Impurities-Procedures. Second Supplement," Vol. 38, 2015, pp. 1-5.

4) "European Pharmacopeia $10^{\text {th }}$ edition," chapter 2.4.20, 2019, pp. 144-147.

5) "Supplement II to the Jpapanese Pharmcopoeia $17^{\text {th }}$ edition," chapter 2.66, 2019, pp. 2893-2896.

6) Balaram V., Trends Analyt. Chem., 80, 83-95 (2016).

7) Lewen N., Mathew S., Schenkenberger M., Raglione T., J. Pharm. Biomed. Anal., 35, 739-752 (2004).

8) Rao N. R., Talluri K. N. V. M., J. Pharm. Biomed. Anal., 43, 1-13 (2007). https://www.sciencedirect.com/science/article/abs/pii/ S0731708506004547?via\%3Dihub

9) Stoving C., Jensen H., Gammelgaard B., Sturup S., J. Pharm. Biomed. Anal., 84, 209-214 (2013).

10) Narukawa T., Iwai T., Chiba K., J. Anal. At. Spectrom., 32, 1547$1553(2017)$.

11) Harigaya K., Kuwahara Y., Nishi H., Chem. Pharm. Bull., 56, 475-479 (2008).

12) Barin S. J., Tischer B., Picoloto S. R., Antes G. F., Silva B. E. F., Paula R. F., Flores M. M. E., J. Anal. At. Spectrom., 29, 352-358 (2014).

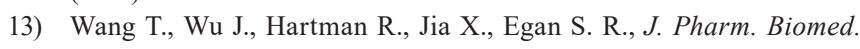
Anal., 23, 867-890 (2000).

14) Muller I. E., Souza P. J., Muller C. C., Muller H. L. A., Mello A. P., Bizzi A. C., Talanta, 156-157, 232-238 (2016).

15) Li G., Schoneker D., Ulman L. K., Sturm J. J., Thackery M. L., Kauffman F. J., J. Pharm. Sci., 104, 4197-4206 (2015).

16) Muller H. L. A., Mello A. P., Mesko F. M., Duarte A. F., Dressler L. V., Muller I. E., Flores M. M. E., J. Anal. At. Spectrom., 27, 1889-1894 (2012).

17) Rudovica V., Viksna A., Actins A., J. Pharm. Biomed. Anal., 91, 119-122 (2014).

18) Sołtyk K., Łozak A., Ostapczuk P., Fijałek Z., J. Pharm. Biomed. Anal., 32, 425-432 (2003).

19) Hoecke V. K., Catry C., Vanhaecke F., J. Anal. At. Spectrom., 27, 1909-1919 (2012)

20) Venzago C., Popp M., Kovac J., Kunkel A., J. Anal. At. Spectrom., 28, 1125-1129 (2013).

21) Chahrour O., Malone J., Collins M., Salmon V., Greenan C., Bombardier A., Ma Z., Dunwoody N., J. Pharm. Biomed. Anal., 145, 84-90 (2017)

22) Fischer L., Zipfel B., Koellensperger G., Kovac J., Bilz S., Kunkel A. Venzago C., Hann S., J. Pharm. Biomed. Anal., 95, 121-129 (2014).

23) Gu X., Zhu S., Yan L., Cheng L., Zhu P., Zheng J., J. Anal. At. Spectrom., 36, 512-517 (2021). 